\title{
Behavior of the Mitochondria in Cell Division, with Evidence Concerning the Kinetic Function ${ }^{1}$
}

Hiroshi Nakahara

\author{
Zoological Institute, Faculty of Seience, Hokkaido University
}

Received April 23, 1952

Recent studies on the kinetic aspects of cell division have progressively been establishing the continuous existence of a close functional relation between the nucleus and the cytoplasm. Especially modern interest has been concerned with the function of the spindle body, centrosome, astral rays, and some other cellular components in relation to the mechanism of cell division, and many new findings have been announced in this field by recent cytologists. While earlier investigations have demonstrated that mitochondria are practically omnipresent in animal cells, the significance and role of this remarkable cytoplasmic component in the course of cell division has not been clearly defined as yet from the kinetic viewpoint. Included in this early work there were a few studies on the mitochondria during cell division, and the most generally accepted hypothesis is that mitochondria play an important role in cellular metabolism (Dalton 1951). Cowdry (1914) found no significant changes in the number of mitochondria during cell division in embryonic cells. Later workers on the chemical characterization of mitochondria give evidence that mitochondria are apparently the sole carriers of certain enzymes (Hogeboom, Schneider \& Pallade 1948, Kennedy \& Lehninger 1948, Tsujita 1948 a). Other authors emphasize that mitochondria are concerned with oxidation and reduction phenomena in the cytoplasm (Meisel 1945, Tsujita $1948 \mathrm{~b}$ ), or that they are closely connected with secretory activity of the cell (Appregarth \& Koneff 1946).

Thus, the demonstration of the presence of mitochondria in all cell types and their significant function in cellular metabolism lead to the supposition that mitochondria should be one of the most important cellular components to maintain the physiological performance of living phenomena of the cell. Here, the role of mitochondria in the kinetic phase of cell division attracts the author's attention, since this field of research has remained unexplored. Accordingly, the present study was undertaken to investigate the kinetic role and behavior of mitochondria during cell division. Generally, normal tissue of the animal is not the

I Contribution No. 269 from the Zoölogical Institute, Faculty of Science, Hokkaido University, Sapporo, Japan.

Aided by a grant from the Scientific Research Fund of the Ministry of Education. 
material of choice for studies on cell division because of the relative scarcity of mitotic figures. In this study, therefore, male germ cells of grasshoppers (Podisma sapporense), in the course of maturation division were adopted as material, since they are obtainable in a good number with facility. By means of the hanging-drop method, the behavior of mitochondria through the course of cell division was successively traced in living spermatocytes with the use of the phase-contrast microscope, under both normal and experimentally induced abnormal conditions.

The auther wishes to express his cordial thanks to Professor Sajiro Makino for his earnest guidance and encouragement shown during the course of the present work. Acknowledgements should also be extended to Professor Kyojiro Shimakura of the Obihiro Zootechnical College, for his kind advice concerning technique and for valuable suggestions.

\section{Method}

The present study was carried out with male germ cells of the grasshopper, Podisma sapporense Shiraki, abundant during early summer in the neighborhood of Sapporo. The larger part of the experiments was based on the primary spermatocytes derived from adult specimens and occasionally from nymphal specimens.

To trace the regular course of the normal spermatocyte division in the living condition, the hanging-drop method only was used with fresh material mounted with body fluid. Small parts of testicular follicles were placed on a clean coverglass and the adhering tissues were gently removed. By carefully cutting the follicle wall with a sharp knife, germ cells are obtained on the cover glass. To the germ cells a small amount of body fluid from the operated animal was added. Then the coverglass thus prepared was inverted over a hollow-slide. This procedure requires extra care and quickness. The edge of the coverglass was sealed with liquid paraffin. The preparation is thus readied for study under microscope.

In the experimental procedure, the germ cells were treated with two kinds of chemicals, caffeine and acriflavine as follows: Chemically pure caffeine crystals were dissolved in proportion of 1 per cent in glucose solution prepared with $6.37 \mathrm{gr}$. of glucose in $100 \mathrm{cc}$ of distilled water. ${ }^{1}$ In the case of acriflavine, the pure drug was dissolved in RingerLocke-Barta's solution ${ }^{2}$ in a concentrations of both 0.05 per cent and

1 In this solution, the spermatocytes of Podisma continue to divide in normal manner (Shimakura unpublished).

2 According to Kanô (1951), in Ringer-Locke-Barta's solution the spermatocytes of Podisma proceed in their meiotic divisions without showing any remarkable harmful effect for a considerable length of time. 
0.2 per cent was utilized. $0.02 \mathrm{cc}$. to $0.05 \mathrm{cc}$. of the mixtures thus prepared were injected per individual in its abdominal cavity. The operated animals were left for about 60 minutes in the case of caffeine and for about 30 minutes in the case of acriflavine. Then the germ cells were removed from testicular follicles, mounted with their own body fluid. And the hanging drop preparation was made according to the procedure described above.

For examination, the phase-contrast microseope ${ }^{3}$ only was used. Such a microscope served to distinguish clearly both the chromosomes and mitochondria from the eytoplasm in fresh, non-stained condition.

The experiments to be described were carried out in the early summers of 1950 and 1951, at room temperatures ranging from $20^{\circ} \mathrm{C}$ to $26^{\circ} \mathrm{C}$.

\section{Observations}

The observations to be described below deal exclusively with the division of primary spermatocytes; the course of division was traced suceessively in a single cell from metaphase to telophase, with special attention to the behaviour of the mitochondria.

1) Behaviour of the mitochondria during the course of cell division in the untreated material

At metaphase, the primary spermatocyte contains large amounts of mitochondria which are short thread-like and fragmental in appearance; they are distributed in irregular manner being scattered throughout the cytoplasm without showing definite orientation (Fig. 1). Especially they are observed gathering around the equatorial plate. At this stage the mitochondria show rather less sharp contrast from the cytoplasm than they do in the later stages.

At the onset of anaphase, the mitochondria begin to take definite orientation in arrangement; they rearrange themselves so as to lie with their long axis nearly parallel to the spindle axis. They seem at this stage to adhere to the outer surface of the spindle body. At the same time, each of them shows considerable elongation. Probably the elongation of mitochondrial elements is due to end-to-end connection of two or more elements in a linear series (Figs. 2-3).

With the separation of chromosomes in anaphase, the cell body elongates along the spindle axis. The mitochondria also arrange themselves longitudinally parallel to the long axis of the cell body, being collected into a few bundles (Figs. 4-5). Then they migrate towards the poles along the spindle body in the form of bundles, simultaneously with the separation of chromosomes. At telophase when each of

The phase-contrast microscope was prepared in the Physical Laboratory under the direction of Professor T. Hori to whom the author's hearty thanks are due. 
the separated daughter chromosomes has reached the opposite poles, the mitochondrial bundles remain stretching like bridges between the two reconstructing telophase nuclei (Fig. 5). The completion of the telophase nuclei is followed by the appearance of the cleavage furrow in the middle part of the cell body. The formation of the cleavage furrow always takes place across the middle part of the mitochondrial

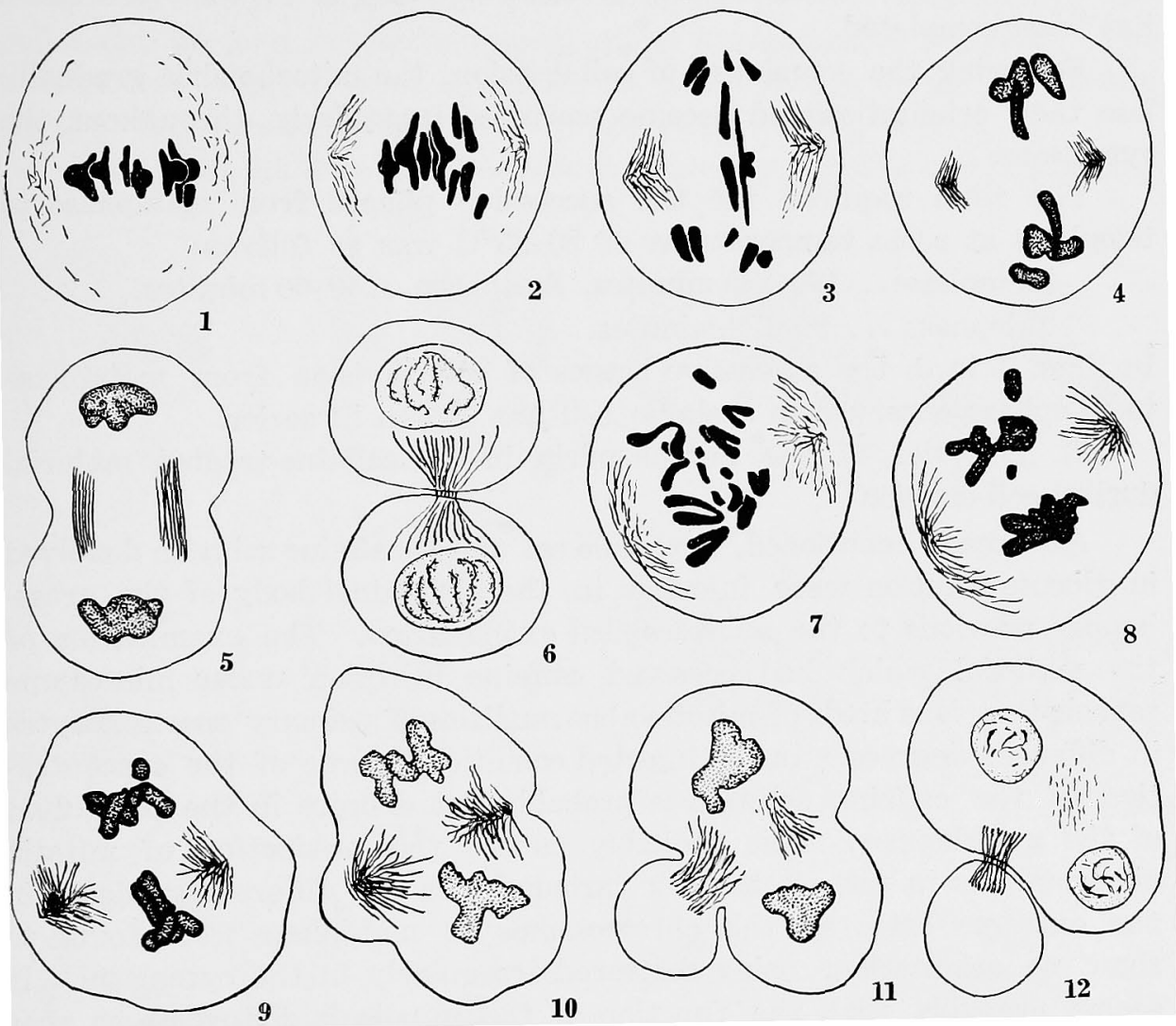

Figs. 1-12. Drawn with Abbe's drawing apparatus, from the hanging-drop preparations. $600 \times$. 1-6, successive stages from metaphase to telophase in a single spermatocyte in the untreated material. 1, metaphase. Mitochondria are distributed scattering throughout the cytoplasm without definite orientation (taken $30^{\prime}$ after preparation). 2 , early anaphase, the mitochondria begin to take definite orientation $\left(44^{\prime}\right) .3$, anaphase ; the oriented mitochondrial elements show stretching $\left(65^{\prime}\right) .4$, the anaphase chromosomes are migrated to poles $\left(103^{\prime}\right)$. 5, the mitochondrial bundles remain stretching between the two telophase nuclei $\left(118^{\prime}\right)$. 6, the cleavage furrow is formed across the middle part of the mitochondrial bundel $\left(166^{\prime}\right)$. 7-12, successive stages from the abnormal cell division in a single cell treated with caffeine. The migration of anaphase chromosomes is disturbed, but mitochondria seem to take their own regular behavior. 7, early anaphase (taken 85' after preparation). 8, the daughter nuclei were formed being nearly approached in position $\left(101^{\prime}\right) .9,\left(130^{\prime}\right) .10,\left(140^{\prime}\right) .11$, the mitochondrial elements rearranged into búndles $\left(150^{\prime}\right)$. 12, formation of a non-nucleated cytoplasmic bud. The cleavage furrow is formed across the middle part of the mitochondrial bundle $\left(195^{\prime}\right)$. 
bundles stretching between two nuclei (Fig. 6). The furrow becomes narrower with time, leading to the complete constriction of the cell body into two daughter cells. At the time when the cell body has completely divided, the mitochondrial bundles still remain connecting two daughter cells, with naked appearance outside the cytoplasm. The mitochondrial connection bridging the two separated daughter cells remain in situ for a considerable length of time, after the cell division has been completed.

Following the completion of cell division, the mitochondria gradually lose their orientation and become scattered irregularly throughout the cytoplasm.

The time required for the successive phases from metaphase to telophase at room temperatures of $20-25^{\circ} \mathrm{C}$ was as follows:

Metaphase...180-240 minutes, Anaphase...40-60 minutes,

Telophase ....90-120 minutes.

In Figs. 1 to 6 , the successive stages of cell division from metaphase to telophase observed in a single cell are shown in series.

2) Behavior of the mitochondria in the caffeine-treated material during cell-division

As already mentioned, $0.02-0.05$ ce. of $1 \%$ caffeine solution dissolved in glucose solution were injected in the abdominal body of the grasshopper previous to the microscopical examination. The examination of the material which had received caffeine injection under microscope revealed various kinds of mitotic abnormalities of primary spermatocytes in different degrees. In the injected condition degree of the concentration of the caffeine solution is probably not definite in the body fluid of the grasshopper. This probably causes the production of mitotic abnormalities in respect to both various kinds and different grades. In the extreme case, all the chromosomes at metaphase were found to show no orientation, being scattered irregularly in the cytoplasm. It seems probable that the function of the spindle is disturbed, so that the chromosome behavior become extremely irregular, resulting in a complete failure to separate. But, in the case when the influence of caffeine seems not very serious, the chromosomes appear at metaphase with rather regular features. The majority of such cells proceed to anaphase, but the migration of chromosomes to the poles showed disturbance to a considerable degree. The two daughter nuclei were formed frequently being close together in position (Figs. 7-10, 25). In the other case, stickiness of chromosomes was induced by the drug which caused the incomplete anaphase separation of chromosomes. This resulted in the formation of the restitution-nucleus (Figs. 14-16, 19-22).

In every case of the abnormalities of the chromosome behavior as above described, however, both the activity and behavior of the 
mitochondria seem to unaffected. In other words, the mitochondria appear to follow their own regular behavior during cell division, without being influenced by the induced abnormal behavior of chromosomes. Through the stages from metaphase to anaphase, the mitochondrial elements rearranged themselves into bundles as seen in the untreated material, showing characteristic orientation along the spindle body. Then they elongated simultaneously with the partial elongation of the cell body, as seen in the telophase cell of the untreated material. The constricting furrow next appeared to form always across the middle part of the mitochondrial bundle (Fig. 10-12, 16-18).

Figs. 7 to 12 show the successive stages in a single cell illustrating
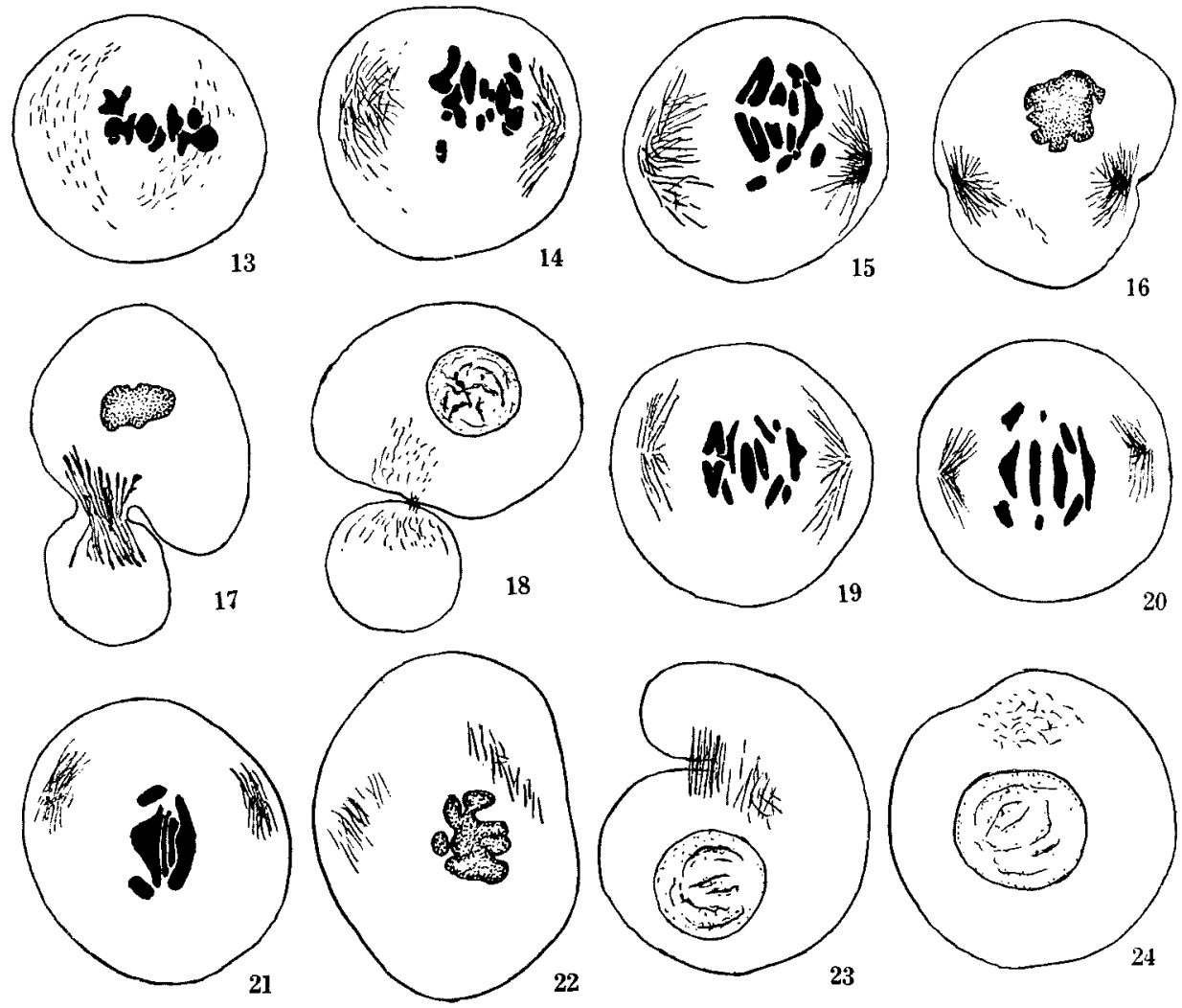

Figs. 13-24. 13-18, successive stages in the formation of a non-nucleated cytoplasmic bud and a cell containing a restitution-nucleus, from the caffeine-treated material. 13, metaphase, chromosomes appear with their regular arrangement $\left(47^{\prime}\right)$. 14, early anaphase $\left(102^{\prime}\right)$. 15, disturbance of chromosomal migration $\left(113^{\prime}\right)$. 16, formation of a restitution-nucleus $\left(176^{\prime}\right)$. 17, formation of cleavage furrow across the middle part of the mitochondrial bundles $\left(245^{\prime}\right)$. 18, formation of a non-nucleated cytoplasmic bud $\left(310^{\prime}\right)$. 19-24, successive stages of the incomplete formation of the furrow. 19, early anaphase $\left(10^{\prime}\right) .20,\left(24^{\prime}\right) .21$, inhibition of the chromosomal migration $\left(34^{\prime}\right)$. 22, formation of a restitution-nucleus $\left(50^{\prime}\right) . \mathbf{2 3}$, incomplete formation of the furrow $\left(70^{\prime}\right) .24$, failure of the formation of the non-nucleated bud $\left(160^{\prime}\right)$. 
the formation of an anucleated cytoplasmic bud and a binucleate cell. In Figs. 13 and 18 are also shown successive stages in the formation of
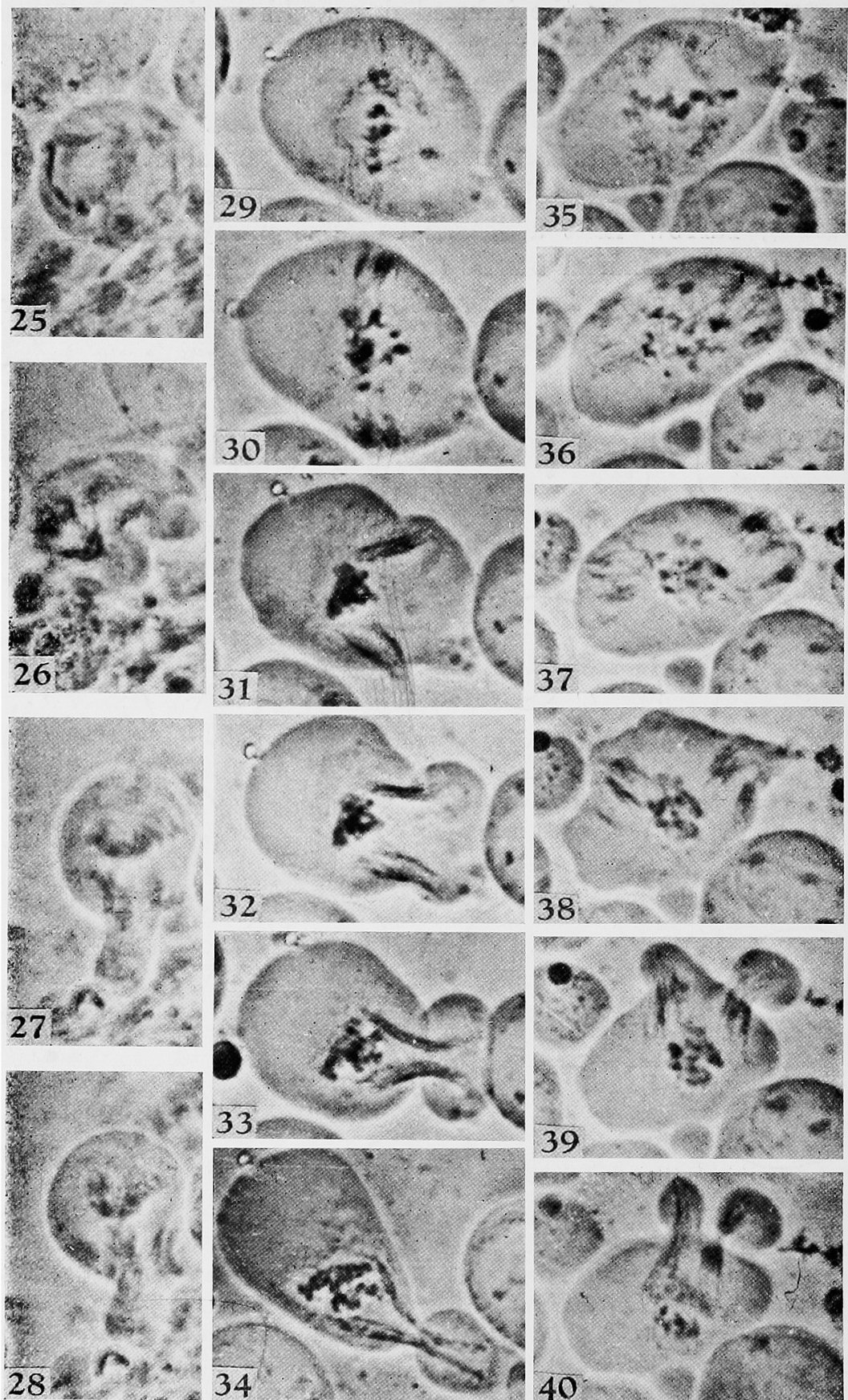

Figs. 25-40. 25-28, photomicrographs. $600 \times$. Successive stages of the formation of an anuclear bud; the same as Figs. 13-18. 25, anaphase (taken 159' after preparation). 26, formation of a restitution nucleus (187'). 27, formation of an anucelar bud (214'40' $)$. 
an anucleated cytoplasmic bud and a cell containing a restitution nucleus. Further, Figs. 19 to 24 are the successive stages showing the failure of the formation of an anucleated bud, due to the incomplete formation of the furrow.

3) Behavior of the mitochondria in the acriflavine-treated material during cell division

In the material which had received $0.05 \%$ acriflavine injection, the majority of germ cells were observed to complete their course of division and a few showed stickiness of chromosomes in the anaphase stage.

After the treatment with $0.2 \%$ acriflavine solution, germ cells displayed various kinds of mitotic abnormalities in different degree, as was the case with the caffeine treatment. On the whole, the effect of acriflavine on the behavior of chromosomes approaches that of caffeine: The abnormal figures here produced were nearly similar to those produced by caffeine, though the influence upon chromosomes seems to be a little more intense in the acriflavine treatment than in the caffeine. Nevertheless, the mitochondria are capable of maintaining their characteristic behavior. For examples, Figs. 29 to 34 are successive stages of the abnormal division induced by acriflavine observed in one and the same spermatocyte; the chromosomes failed to migrate to the poles, due probably to stickiness of chromosomes, while the mitochondrial bundles elongated in the same manner as the regular anaphasic spindle, and the cleavage furrow was formed across the middle parts of the mitochondrial bundles (Figs. 32-34). Then an anucleated cytoplasmic bud was cleft out of the mother cells (Fig. 34). Figs. 35 to 40 also show successive stages of induced abnormal division in a single spermatocyte, in which the formation of two non-nucleated cytoplasmic buds are depicted. In this case too, the formation of the cleavage furrow took place across the middle parts of the elongated mitochondrial bundles (Fig. 40).

\section{Considerations}

Concerning the mechanism involving the formation of cleavage furrow, various hypotheses have been published. Some early workers stated that the formation of the cleavage furrow in cell division occurs in

28, (217'15'). 29-34 and 25-40, successive stages of the abnormal cell divisions induced by acriflavine. All are photomicrographs. $600 \times$. 29-34, the failure of chromosomal migration, and the formation of an anuclear cytoplasmic bud. 29, metaphase $\left(391^{\prime}\right)$. 30, early anaphase, the chromosomes failed to migrate to poles $\left(432^{\prime}\right)$. 31, $\left(484^{\prime}\right)$. 32, stretehing of mitochondrial bundle, and formation of the furrow $\left(518^{\prime}\right)$. 33, $\left(565^{\prime}\right)$. 34, constriction of an anuclear bud $\left(605^{\prime}\right)$. 35-40, the formation of two anuclear cytoplasmic buds. 35, metaphase $\left(315^{\prime}\right)$. 36, anaphase, the chromosomes failed to migrate to poles $\left(374^{\prime}\right)$. 37, $\left(406^{\prime}\right)$. 38, stretching of mitochondrial bundles in two groups $\left(437^{\prime}\right)$. $\mathbf{3 9}$, furrow was formed across the middle part of the mitochondrial bundle $\left(463^{\prime}\right) .40$, formation of two cytoplasmic buds $\left(510^{\prime}\right)$. 
connection with the differrentiation of surface-tension of the cytoplasmic surface between the pole and the equator. Berlar̆ (1929) accepted this conception in explaining the related phenomenon in the grasshopper spermatocytes. Chambers (1919) proposed the view that the cleavage results from the gelation of asters. This view was supported by Gray (1924) and some others from the results from experiments with seaurchin eggs. According to Marsland (1938, 1939) and Chambers (1938), who worked with sea-urchin eggs, the cleavage furrow results from the intrusion upon the mitotic axis of a specialized cortical layer of gelated protoplasm, which may be compared with the plasmagel layer of amoeboid cells.

Recently Ris (1949), in some experimental studies with grasshopper spermatocytes presented interesting evidence on the relation of spindle elongation to cytoplasmic division. According to him, when the spindle does not elongate normally, the cleavage furrow is always delayed or does not appear at all. He observed the formation of cleavage furrow with no nuclear division in living cell after X-radiation, and stated that this abnormality is attributable to abnormal spindle elongation caused by chromosome stickiness. These results lead him to conclude that the formation of cleavage furrow is dependent upon cell elongation caused by the stretching of the spindle.

Dan, K. (1943) and Dan, J. C. (1948), basing their views on the results from their studies of fresh marine eggs, considered that the astral rays serve as guy ropes which exert a pull on the sub-polar and equatorial surfaces of egg cortex in such a way as to induce the cleavage furrow.

So far as the reported cases have shown, as above, the mechanism of cleavage seems to be connected with the activity of the spindle, aster and surface layer of the cytoplasm. There is no author who has directed his attention towards the function or significance of mitochondria during cell division. The results of the present experiments lead to the conclusion that the mitochondria take a significant part in the formation of the cleavage furrow in cell division.

The results of the present experiments indicate that the division of the cell body may be independent of the nuclear division, in the cases of either caffeine or acriflavine treatments. The studies on the induced abnormal divisions lead to the conclusion that the failure of migration of separated chromosomes to the poles is probably due to the defect of chromosomal potency, or else to the spindle disturbance, but not necessarily to stickiness of chromosomes. Chromosome stickiness at anaphase was often met with in the material which received caffeine injection. But it was not always concerned with the failure of migration of separated chromosomes, and the latter pass incompletely 
to poles in most cases. After the acriflavine treatment, there also occurs stickiness of chromosomes. Nevertheless, the mitochondria follow their characteristic behavior, and the cleavage furrow is formed across their middle parts without exception. Thus, the evidence presented here seems to indicate that the formation of the cleavage furrow at telophase takes place in close association with the characteristic behavior of mitochondria at anaphase. In every case of either normal or abnormal separation of the chromosomes, the mitochondria always show their characteristic behavior and the cleavage furrow is formed across the middle part of the mitochondrial bundles. At present there remains a question whether or not the elongation of mitochondria at anaphase and the formation of cleavage furrow at telophase are attributable to the activity of the mitochondria alone. However, the following statement may be allowed from the results of this study, viz., that the activity of mitochondria is not in the least under the control of either both the spindle body or aster.

\section{Summary}

The kinetic behavior of the mitochondria in the course of cell division was successively traced in fresh grasshopper spermatocytes with the use of a phase-contrast microscope, under both normal and induced abnormal conditions. In every case of either normal or abnormal condition of the chromosomes observed during the period from metaphase to telophase, the mitochondria always showed their characteristic behavior in the course of division, and the cleavage furrow is formed without exception in close connection with the characteristic behavior of the mitochondria. The evidence here presented seems to indicate that the mitochondria play a significant part in the formation of the cleavage furrow in cell division.

\section{Literature}

Applegarth, A. P. and A. A. Koneff 1946. The effect of Alloxan diabetes on the Golgi apparatus and mitochondria of thyroid gland in the rat. Anat. Rec. 96 : 13-19.

Bělař, K. 1929. Beiträge zur Kausalanalyse der Mitose. II. Untersuchungen an den Spermatocyten von Chorthippus (Stenobothrus) lineatus Panz. Arch. f. Entwicklungsmech. 118 : 359-484.

Chambers, R. 1919. Changes in protoplasmic consisteney and their relation to cell division. J. Gen. Physiol. 2 : 49-68.

- 1938. Structural and kinetic aspects of cell division. J. Cell. Comp. Physiol. 12 : 149-165.

Cowdry, E. V. 1914. The development of the cytoplasmic constituents of the nerve cells of the chick. 1. Mitochondria and Newrofibrils. Amer. J. Anat. 15 : 389-429.

Dalton, A. J. 1951. Cytoplasmic changes during cell division with reference to mitochondria and the Golgi substance. Ann. New York Acad. Sci. 51 : 1295-1302. 
Dan, J. C. 1948. On the mechanism of astral cleavage. Physiol. Zoöl. 21 : 191-218.

Dan, K. 1943. Behavior of the cell surface during cleavage. VI. On the mechanism of cell division. J. Fac. Sci., Tokyo Imp. Univ. Ser. IV 6: 323-368.

Gray, J. 1924. The mechanism of cell division. I. The forces which control the form and cleavage of the eggs of Echinus esculentus. Proc. Cambridge Phil. Soc. 1 : 164-188.

Hogeboom, G. H., W. C. Schneider and G. E. Pallade 1948. Cytochemical studies of mammalian tissues. I. Isolation of intact mitochondria from rat liver; some biochemical properties of mitochondria and submicroscopic particulate material. J. Biol. Chem. 172: 619-636.

Kanô, K. 1951. Some observations of abnormal divisions in grasshopper germ cells after treatment with hypotonic and hypertonic solutions. J. Fac. Sci. Hokkaido Univ. Ser. VI, Zool. $10: 139-149$.

Kennedy, E. P. and A. L. Lehninger 1948. Intracellular structures and the fatty acid oxidase system of rat liver. J. Biol. Chem. 172: 847-848.

Marsland, D. A. 1938. The effects of the high hydrostatic pressure upon cell division in Arbacia eggs. J. Cell. Comp. Physiol. 12: 57-70.

- 1939. The mechanism of cell division: hydrostatic pressure effects upon dividing egg dells. Ibid. $13: 15-22$.

Meisel, M. N. 1945. On the morphology and functions of the chondriosomic apparatus of a cell. Bull. eksper. biologie imeditsini 19: 16-19.

Ris, H. 1949. The anaphase movement of chromosomes of the grasshopper. Biol. Bull. 96: 90-106.

Tsujita, M. 1948 a. Cytological studies of the Malpighian tubules in the silkworm larva. II. Relation between chondriosomes and "Lactoflavine". (In Japanese). Bull. Sericul. Exp. Sta. 12 : 649-666.

- $1948 \mathrm{~b}$. Studies of the mid-gut epithelium in the silkworm. II. On the oxidase reaction of the mid-gut epithelium in the silkworm larva. (In Japanese). Ibid. 12 : $667-678$. 